\title{
Wettability and Reliability for Double-Sided Assembly with Chip Connection (C2) Flip-Chip Technology
}

\author{
Hirokazu Noma*, Yukifumi Oyama*, Hidetoshi Nishiwaki*, Masahide Takami*, Toshiyuki Takatani*, \\ Kazushige Toriyama* and Yasumitsu Orii** \\ *Microelectronics Japan, IBM Japan, Ltd., 338, Enpukuji-cho, Muromachi-dohri, Oike Sagaru, Nakagyo-ku, Kyoto-shi, Kyoto 604-8175, Japan \\ **Tokyo Research Laboratory, IBM Japan, Ltd., 1623-14, Shimo-tsuruma, Yamato-shi, Kanagawa 242-8502, Japan
}

(Received August 7, 2009; accepted November 12, 2009)

\begin{abstract}
With the continued shrinking of the system-in-package, there is increasing pressure to use double-sided flip-chip assembly to reduce the size of systems. The same thermal treatment used to assemble the flip-chip on one side is also done on the other side of the substrate. A concern is the low wettability of the solder when assembling the second flip-chip. The wettability of solder depends on the surface treatment of the pads of the substrate. Various surface treatments such as Organic Solderability Preservative (OSP), Electroless Sn plating (E-less Sn), and Direct Immersion Gold (DIG) are evaluated. OSPs with high solubility into flux showed good wettability with adequate margins. Even though E-less Sn showed good wettability, the margins were insufficient. Thin DIG showed poor wettability because the Au diffused into the $\mathrm{Cu}$ during the thermal treatments. Reliability tests were performed on the OSPs which showed good wettability. Good reliability was confirmed for the double-sided flip-chip packages.
\end{abstract}

Keywords: Chip Connection, Flip-Chip, Surface Treatment, System-in-Package, Thermal Treatment, Assembly, Double-Sided

\section{Introduction}

Double-sided flip-chip assembly can reduce the area of a system-in-package.[1] However, double-sided flip-chip assembly is different from single-sided flip-chip assembly in two aspects. First, the thermal treatment to assemble the first side is also done on the other side. Therefore, the first thermal treatment tends to decrease the wettability of the solder for the second heating because of temperatureinduced oxidation of the pads.[2] Second, the thermal cycle reliability of the double-sided package tends to be worse than the single-sided package due to the differences in the strain of the solder joints.

For fine-pitch flip-chip interconnections, IBM developed Chip Connection (C2) technology in which dies with $\mathrm{Cu}$ posts and $\mathrm{Sn}-\mathrm{Ag}$ solder bumps are connected on an organic substrate with a reflow process using no-clean flux.[3] The no-clean flux is used because flux cleaning is difficult for fine-pitch interconnections due to the narrow gap between the chip and the substrate. A high activity flux which requires cleaning after reflow can be used for double-sided surface mount technology (SMT). However, the high activity flux cannot be used for fine-pitch interconnections. Therefore, double-sided flip-chip assembly is more difficult than double-sided SMT.

In this paper, the wettability and reliability during doublesided flip-chip assembly are evaluated with various surface treatments on the copper pads of the substrate.

\section{Experiments}

\subsection{Process flow}

C2 technology was used for the double-sided assembly. The process flow for the double-sided flip-chip package is shown in Fig. 1(a). First, the flip-chip joint and the underfill are done on one side (the first side). Then, the flip chip joint and the underfill are done on the other side (the second side).

The purpose of our evaluation was to check the wettability. Therefore, for simplicity, the same thermal history as the first side assembly was used instead of the chip assembly. Then the chip was assembled on the second side. The processing flow for the wettability test is shown in Fig. 1(b). 
Two conditions were used to check the margin of the wettability.

(1) The standard thermal history (Nominal thermal history).

(2) An excessive thermal history for margin evaluation (Excessive thermal history).

The differences between the nominal and excessive thermal histories are shown in Table 1 . The process with the highest temperature is reflow and the second hottest is for curing the underfill. For the excessive thermal his- tory, reflow was done twice before assembling the second side and the time for curing the underfill was twice as long as the standard condition. Prebaking is a process to remove moisture from the organic substrate to prevent blisters during reflow. For the excessive thermal history, the prebaking time was six times as long as in the standard condition as though the substrate was baked several times.

\subsection{Wettability tests}

Wettability was examined using three tests:

(1) Electrical connection

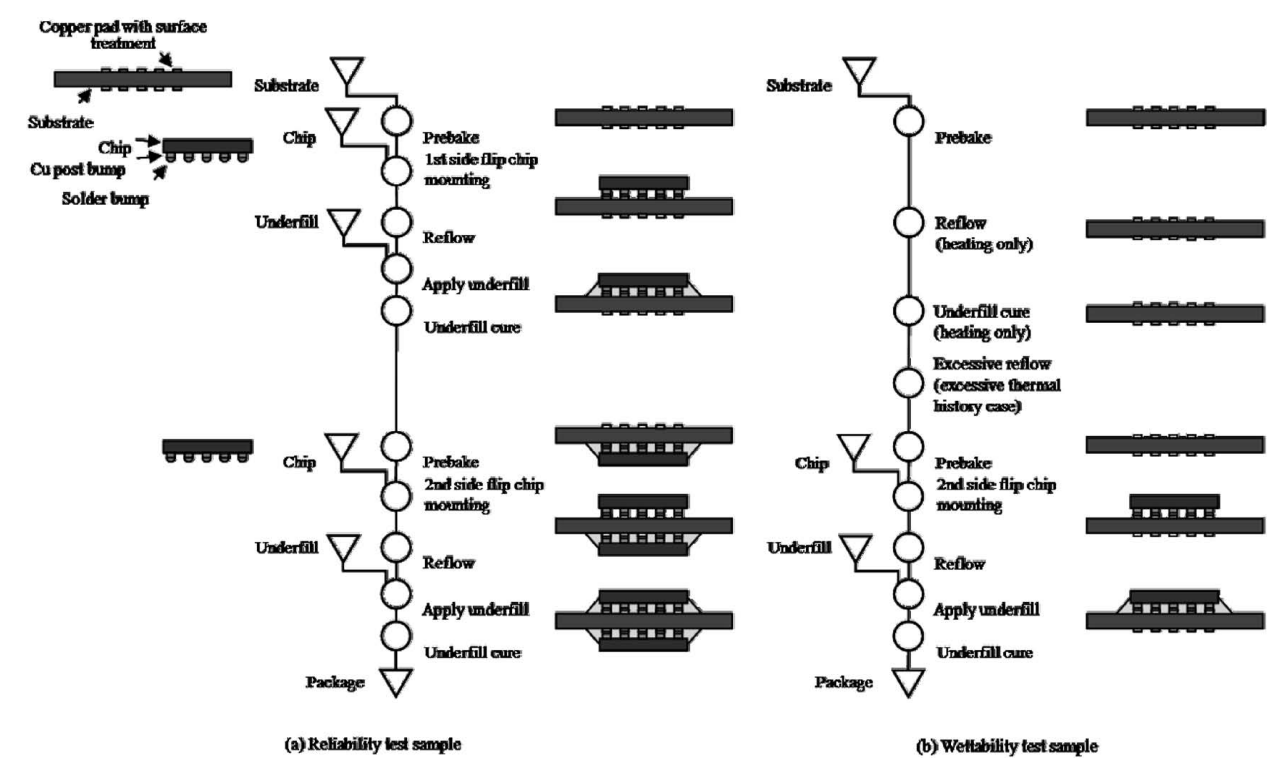

Fig. 1 Process flow of double-sided flip-chip assembly with Chip Connection (C2).

Table 1 Thermal history.

\begin{tabular}{|c|c|c|c|}
\hline \multirow[b]{2}{*}{ Processes } & \multirow{2}{*}{$\begin{array}{c}\text { Reliability test } \\
\text { Nominal } \\
\text { thermal history }\end{array}$} & \multicolumn{2}{|c|}{ Assembly test } \\
\hline & & $\begin{array}{l}\text { Nominal } \\
\text { thermal history }\end{array}$ & $\begin{array}{l}\text { Excessive } \\
\text { thermal history }\end{array}$ \\
\hline Prebake substrate & Standard condition & Standard condition & $\begin{array}{l}6 \text { times as long as standard } \\
\text { condition }\end{array}$ \\
\hline $\begin{array}{l}\text { 1st side } \\
\text { flip-chip mount }\end{array}$ & Standard condition & Skip & Skip \\
\hline Reflow & Standard condition & Standard condition & Standard condition \\
\hline Apply underfill & Standard condition & Skip & Skip \\
\hline Cure underfill & Standard condition & Standard condition & $\begin{array}{l}\text { Twice as long as standard } \\
\text { condition }\end{array}$ \\
\hline Excessive reflow & None & None & Once at standard condition \\
\hline Prebake substrate & Standard condition & Standard condition & $\begin{array}{l}6 \text { times as long as standard } \\
\text { condition }\end{array}$ \\
\hline $\begin{array}{l}\text { 2nd side } \\
\text { flip-chip mount }\end{array}$ & Standard condition & Standard condition & Standard condition \\
\hline Reflow & Standard condition & Standard condition & Standard condition \\
\hline Apply underfill & Standard condition & Standard condition & Standard condition \\
\hline Cure underfill & Standard condition & Standard condition & Standard condition \\
\hline
\end{tabular}


Table 2 Surface treatments.

\begin{tabular}{|c|c|c|c|}
\hline Surface treatment & $\begin{array}{c}\text { Coated/Plated material } \\
\text { on copper pads }\end{array}$ & Coating/Plating thickness & Copper pad pitch \\
\hline OSP-A & Benzotriazole & $0.001 \mu \mathrm{m}$ & $80 \mu \mathrm{m}$ \\
\hline OSP-B & Imidazole complex & $0.2 \mu \mathrm{m}$ & $80 \mu \mathrm{m}$ \\
\hline \multirow[t]{2}{*}{ OSP-C } & Imidazole complex & $0.2 \mu \mathrm{m}$ & $80 \mu \mathrm{m}$ \\
\hline & & $0.3 \mu \mathrm{m}$ & $80 \mu \mathrm{m}$ \\
\hline OSP-D & Imidazole complex & $0.2 \mu \mathrm{m}$ & $80 \mu \mathrm{m}$ \\
\hline E-less Sn & $\mathrm{Sn}$ & $1.2 \mu \mathrm{m}$ & $80 \mu \mathrm{m}$ \\
\hline \multirow[t]{2}{*}{ DIG } & $\mathrm{Au}$ & $0.03 \mu \mathrm{m}$ & $50 \mu \mathrm{m}$ \\
\hline & & $0.06 \mu \mathrm{m}$ & $50 \mu \mathrm{m}$ \\
\hline
\end{tabular}

After assembling the second side, the electrical connections between the chips and substrate were checked with an electrical tester.

(2) Peeling test

A destructive peeling test was used as a simple test to check the wettability, because poor wettability can be detected immediately after the reflow of the second side. The test chips were peeled off of the substrate to check the wettability based on the modes of fracture. If separation between the solder bumps and the copper pads was found in the peeling test, the wettability of the solder onto the copper pads of the substrate was regarded as poor.

(3) Cross-sectional observation

After curing the underfill on the second side, some of the packages were observed in cross-section to see whether the solder had properly flowed onto the copper pads of the substrates. The numbers of the pads observed were 82 for the $80-\mu \mathrm{m}$-pitch pads and 136 for $50-\mu \mathrm{m}$-pitch pads.

\subsection{Surface treatments}

The evaluated surface treatments used for the evaluations are shown in Table 2. Organic Solderability Preservative (OSP), [2] Electroless Sn plating,(E-less Sn) [2] and Direct Immersion Gold (DIG) [4] were evaluated.

OSP is a process to prevent oxidation on the copper pads, and is used in $\mathrm{C} 2$ technology. When poor wettability was found in the experiments, E-less Sn and DIG were also tested.

Even though oxidation is a concern for Sn because the ionization tendency of $\mathrm{Sn}$ is higher than that of $\mathrm{Cu}$, good wettability due to the melting of Sn during reflow is expected. Sn whiskers[5] are another concern for Sn plating. The Sn plated pads on the substrate were examined before assembly and no whiskers were found with a $40 \mathrm{x}$ microscope.

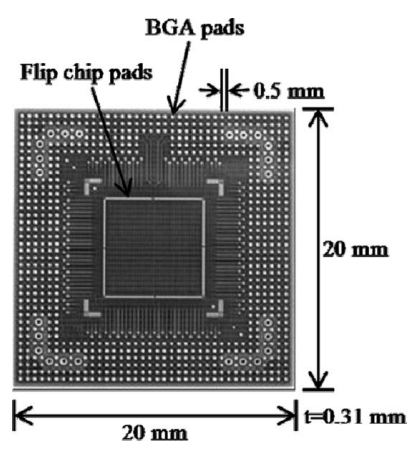

Fig. 2 TEG substrate (80- $\mu \mathrm{m}$ pitch).

DIG is a process to prevent oxidation by coating the copper pads with $\mathrm{Au}$, whose ionization tendency is much lower than $\mathrm{Cu}$. Electroless $\mathrm{Ni} / \mathrm{Au}$ plating [6] is not suitable for fine pitch pads because the Ni layer has a thickness of around $3 \mu \mathrm{m}$. DIG can be used with fine pitch pads because the Ni layer can be eliminated.

\subsection{Test element group (TEG)}

Fig. 2 shows the Test Element Group (TEG) substrate for the evaluation. The size of the substrate is $20 \mathrm{~mm} \times$ $20 \mathrm{~mm} \times \mathrm{t} 0.31 \mathrm{~mm}$, and the size of the chip is $7.3 \mathrm{~mm} \times$ $7.3 \mathrm{~mm} \times \mathrm{t} 0.725 \mathrm{~mm}$. Two types of TEG chips, one with an $80-\mu \mathrm{m}$ pitch, and another with a $50-\mu \mathrm{m}$ pitch, were used. The pads for the flip-chips are arranged peripherally. The numbers of pads were 328 ( 82 bumps on each side) and 544 (136 bumps on each side), respectively.

\section{Results and Discussion}

The results of the evaluation are summarized in Table 3. Good results were obtained with OSP-A and OSP-B.

(1) Electrical connection

An electrical open (NG) was found only in DIG with t0.03 $\mu \mathrm{m}$. Good electrical connections were confirmed in all of the other conditions.

(2) Peeling test 
Table 3 Wettability test results.

\begin{tabular}{|c|c|c|c|c|c|c|}
\hline \multicolumn{2}{|c|}{ Experimental conditions } & \multicolumn{5}{|c|}{ Results } \\
\hline \multirow[t]{2}{*}{ Surface treatment } & \multirow[t]{2}{*}{ Test method } & \multirow[t]{2}{*}{ Unit } & \multicolumn{2}{|c|}{$\begin{array}{l}\text { Nominal } \\
\text { thermal history }\end{array}$} & \multicolumn{2}{|c|}{$\begin{array}{l}\text { Excessive } \\
\text { thermal history }\end{array}$} \\
\hline & & & NG & Tested & NG & Tested \\
\hline \multirow{3}{*}{$\begin{array}{l}\text { OSP-A } \\
\text { t0.001 } \mu \mathrm{m}\end{array}$} & Electrical Connection & Chip & 0 & 3 & 0 & 2 \\
\hline & Peeling Test & Chip & 0 & 1 & 0 & 1 \\
\hline & Cross Section & Bump & 0 & 82 & 0 & 82 \\
\hline \multirow{3}{*}{$\begin{array}{l}\text { OSP-B } \\
\mathrm{t} 0.2 \mu \mathrm{m}\end{array}$} & Electrical Connection & Chip & 0 & 4 & 0 & 1 \\
\hline & Peeling Test & Chip & 0 & 2 & 0 & 1 \\
\hline & Cross Section & Bump & 0 & 82 & 0 & 82 \\
\hline \multirow{3}{*}{$\begin{array}{l}\text { OSP-C } \\
\mathrm{t} 0.2 \mu \mathrm{m}\end{array}$} & Electrical Connection & Chip & 0 & 4 & \multirow{3}{*}{\multicolumn{2}{|c|}{ Not tested }} \\
\hline & Peeling Test & Chip & 0 & 2 & & \\
\hline & Cross Section & Bump & 13 & 82 & & \\
\hline \multirow{3}{*}{$\begin{array}{l}\text { OSP-C } \\
\text { t0.3 } \mu \mathrm{m}\end{array}$} & Electrical Connection & Chip & 0 & 5 & \multirow{3}{*}{\multicolumn{2}{|c|}{ Not tested }} \\
\hline & Peeling Test & Chip & 0 & 3 & & \\
\hline & Cross Section & Bump & 19 & 82 & & \\
\hline \multirow{3}{*}{$\begin{array}{l}\text { OSP-D } \\
\mathrm{t} 0.2 \mu \mathrm{m}\end{array}$} & Electrical Connection & Chip & 0 & 5 & \multirow{3}{*}{\multicolumn{2}{|c|}{ Not tested }} \\
\hline & Peeling Test & Chip & 0 & 3 & & \\
\hline & Cross Section & Bump & 11 & 82 & & \\
\hline \multirow{3}{*}{$\begin{array}{l}\text { E-less Sn } \\
\mathrm{t} 1.2 \mu \mathrm{m}\end{array}$} & Electrical Connection & Chip & 0 & 5 & 0 & 2 \\
\hline & Peeling Test & Chip & 0 & 3 & 0 & 1 \\
\hline & Cross Section & Bump & 0 & 82 & 35 & 82 \\
\hline \multirow{3}{*}{$\begin{array}{l}\text { DIG } \\
\mathrm{t} 0.03 \mu \mathrm{m}\end{array}$} & Electrical Connection & Chip & 1 & 4 & \multirow{3}{*}{\multicolumn{2}{|c|}{ Not tested }} \\
\hline & Peeling Test & Chip & 2 & 3 & & \\
\hline & Cross Section & Bump & & ested & & \\
\hline \multirow{3}{*}{$\begin{array}{l}\text { DIG } \\
\mathrm{t} 0.06 \mu \mathrm{m}\end{array}$} & Electrical Connection & Chip & 0 & 3 & \multirow{3}{*}{\multicolumn{2}{|c|}{ Not tested }} \\
\hline & Peeling Test & Chip & 0 & 2 & & \\
\hline & Cross Section & Bump & 0 & 136 & & \\
\hline
\end{tabular}

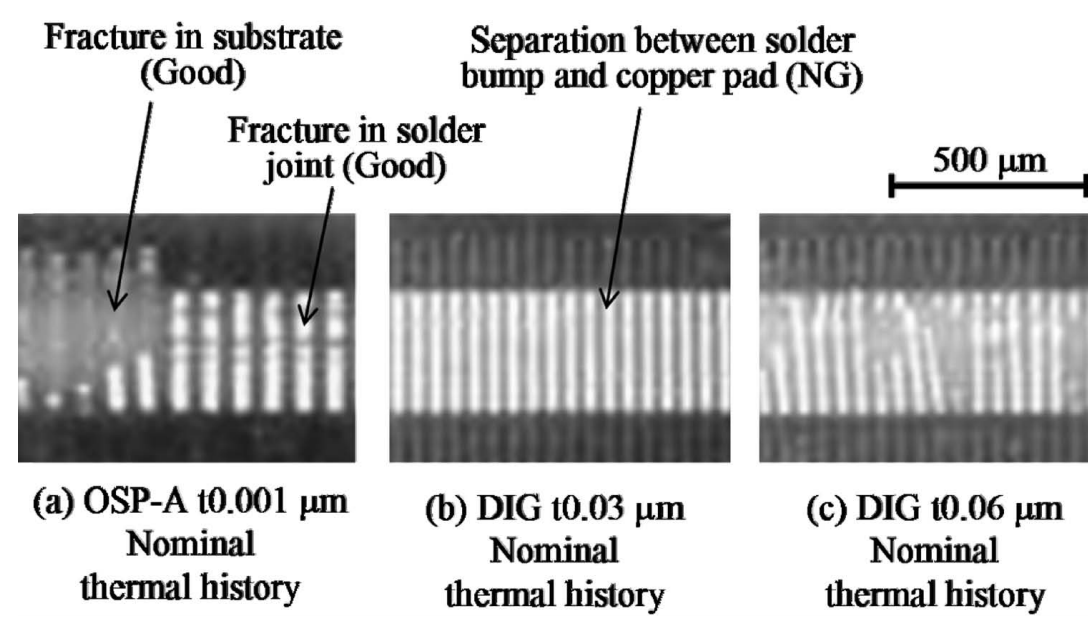

Fig. 3 Planar views of substrates.

Poor wettability in the peeling test was found only in DIG with t0.03 $\mu \mathrm{m}$, as shown in Fig. 3(b). Adequate wettability was found in all of the other conditions. The modes of fracture were in the substrate or in the solder joints, as shown in Figs. 3(a) and (c).

(3) Cross-sectional observations 


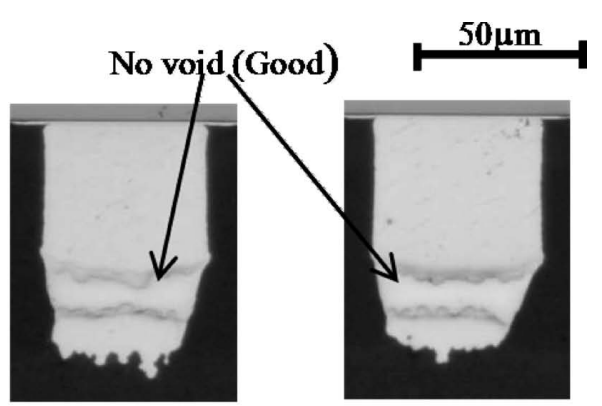

(a) OSP-A t0.001 $\mu \mathrm{m}$ Nominal thermal history

(b) OSP-B

t0.2 $\mu \mathrm{m}$

Nominal thermal history

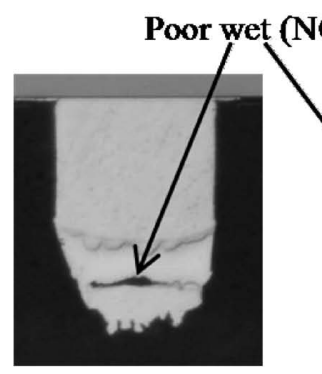

(c) OSP-C t0.3 $\mu \mathrm{m}$ Nominal thermal history (d) E-less Sn t1.2 $\mu \mathrm{m}$

Excessive thermal history

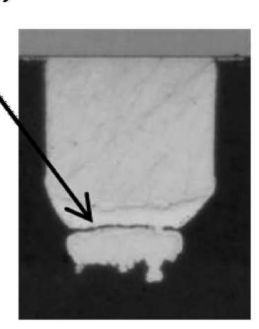

Fig. 4 Cross-sections of solder joints.

As shown in Figs. 4(a) and (b), the solder was well wetted on the pads with OSP-A and OSP-B. Not only the nominal thermal history samples but also the excessive thermal history samples showed good wetting on the pads with OSP-A and OSP-B.

In contrast, OSP-C and OSP-D show poor wettability. An example of a pad with poor wettability is shown in Fig. 4(c). Neither solder nor Intermetallic Compound (IMC) was observed on some parts of the copper pads, which means that the solder was not able to penetrate those areas. Even though the results of the electrical connection and peeling tests were good, the poor wetting was found by observing the solder joint closely in cross-section. The differences in the wetting among the OSPs are due to the differences in the solubilities of the OSPs with the flux used in the assembly process. OSP is performed to prevent oxidation of copper pads. However, if OSP remains during reflow, OSP prevents wetting of solder. OSP which can easily dissolve into a small amount of non-clean flux is desired.

E-less Sn showed good wettability in the nominal thermal history sample. However, poor wettability was found in the excessive thermal history sample as shown in Fig. 4(d). The root causes are (1) too much oxidation of Sn on

Table 4 Reliability test conditions.

\begin{tabular}{ll}
\hline \multicolumn{1}{c}{ Item } & \multicolumn{1}{c}{ Conditions } \\
\hline Precondition & JEDEC Level 3 equivalent \\
Temperature Cycling Test & $-55^{\circ} \mathrm{C}$ to $125^{\circ} \mathrm{C}, 2$ cycles/hour \\
(TC) & \\
Temperature Humidity & $85^{\circ} \mathrm{C}, 85 \% \mathrm{RH}, 3.7 \mathrm{~V}$ \\
Bias Life Test (THB) & \\
\hline
\end{tabular}

Table 5 Reliability test results.

\begin{tabular}{ccc}
\hline \multirow{2}{*}{$\begin{array}{c}\text { Surface } \\
\text { treatment }\end{array}$} & \multicolumn{2}{c}{ Reliability test results } \\
\cline { 2 - 3 } & $\begin{array}{c}\text { Temperature Cycling } \\
\text { Test (TC) }\end{array}$ & $\begin{array}{c}\text { Temperature Humidity } \\
\text { Bias Life Test (THB) }\end{array}$ \\
\hline OSP-A & 3,250 cycles & 1,000 hours \\
t0.001 $\mu \mathrm{m}$ & $30 / 30$ pcs Pass & $16 / 16$ pcs Pass \\
\hline OSP-B & 3,250 cycles & 1,000 hours \\
t0.2 $\mu \mathrm{m}$ & $26 / 26$ pcs Pass & $15 / 15$ pcs Pass \\
\hline
\end{tabular}

the pads which cannot be removed by the reduction effects of the no-clean flux or (2) too much growth of IMC, which changes most of the plated Sn into IMC that does not melt at the reflow temperature.

DIG with $0.03 \mu \mathrm{m}$ showed poor wettability, while DIG with $\mathrm{t} 0.06 \mu \mathrm{m}$ showed good wettability. The reason is the diffusion of $\mathrm{Au}$ into the $\mathrm{Cu}$ pads, which results in oxidation of the copper on the surface.[4]

\section{Reliability Tests}

The reliability tests were performed on OSP-A and OSP$B$. The reliability test conditions are shown in Table 4 and the results are shown in Table 5. Both OSP-A and OSP-B show good reliability in the Temperature Cycling Test (TC) and Temperature Humidity Bias Life Test (THB).

\section{Summary}

The double-sided flip-chip assemblies were evaluated with various surface treatments on the copper pads of the substrate to check the wettability. Not only the heat resistance but also the solubility into flux is important for OSP. In E-less Sn plating, the surface oxidation and IMC growth must be assessed. Using DIG, the surface oxidation of the $\mathrm{Cu}$ due to the $\mathrm{Au}$ diffusion into the $\mathrm{Cu}$ must be assessed.

Reliability tests were performed on the OSPs which showed good wettability. This good reliability was confirmed for the double-sided flip-chip packages with the TC and THB. 


\section{References}

[1] W. Koh, "System in package (SiP) technology applications”, International Conference on Electronic Packaging Technology, pp. 61-66, August 2005.

[2] C. Ryu et al., "Novel Approaches to Current BGA Packaging Challenges”, Electronics Packaging Technology Conference, pp. 1258-1263, December 2008.

[3] Y. Orii et al., "Ultrafine-Pitch C2 Flip Chip Interconnections with Solder-Capped Cu Pillar Bumps”, Electronic Components and Technology Conference, pp. 948-953, May 2009.

[4] D. Kin et al., "Evaluation of DIG (Direct Immersion
Gold) as a New Surface Finish for Mobile Applications”, Electronic Components and Technology Conference, pp. 258-262, June 2006.

[5] J. Lee, "The Sn Whisker Growth Evolution of IC Packaging on the PC Board Assembly”, Electronic Components and Technology Conference, pp. 1964-1970, May 2007.

[6] K. Yokomine et al, Development of electroless $\mathrm{Ni} / \mathrm{Au}$ plated build-up flip chip package with highly reliable solder joints, Electronic Components and Technology Conference, pp. 1384-1392, May 2001. 